\title{
Dynamic translabial ultrasound versus echodefecography combined with the endovaginal approach to assess pelvic floor dysfunctions: How effective are these techniques?
}

\author{
S. M. Murad-Regadas ${ }^{1,2,3}$ - S. A. Karbage ${ }^{2,3,4}$ - L. S. Bezerra ${ }^{2,3,4}$ - F. S. P. Regadas ${ }^{1}$ \\ A. da Silva Vilarinho ${ }^{3}$ - L. B. Borges ${ }^{3}$ F. S. P. Regadas Filho ${ }^{3}$ L. B. Veras ${ }^{1}$
}

Received: 17 February 2017/ Accepted: 7 June 2017/Published online: 3 July 2017

(c) Springer International Publishing AG 2017

\begin{abstract}
Background The aim of this study was to evaluate the role of dynamic translabial ultrasound (TLUS) in the assessment of pelvic floor dysfunction and compare the results with echodefecography (EDF) combined with the endovaginal approach.

Methods Consecutive female patients with pelvic floor dysfunction were eligible. Each patient was assessed with EDF combined with the endovaginal approach and TLUS. The diagnostic accuracy of the TLUS was evaluated using the results of EDF as the standard for comparison.

Results A total of 42 women were included. Four sphincter defects were identified with both techniques, and EDF clearly showed if the defect was partial or total and additionally identified the pubovisceral muscle defect. There was substantial concordance regarding normal relaxation and anismus. Perfect concordance was found with rectocele and cystocele. The rectocele depth was measured with
\end{abstract}

Presented at the American Society of Colon and Rectal Surgery 2016 Annual Meeting, Los Angeles, CA April 30-May 4, 2016.

S. M. Murad-Regadas

smregadas@hospitalsaocarlos.com.br

1 Unit of Pelvic Floor and Anorectal Physiology, Department of Surgery, School of Medicine, Clinical Hospital, Federal University of Ceará, Av Pontes Vieira, 2551, Fortaleza, CE 60130-241, Brazil

2 Unit of Pelvic Floor and Anorectal Physiology, Clinical Hospital, Federal University of Ceará, Fortaleza, CE, Brazil

3 Unit of Pelvic Floor and Anorectal Physiology, Department of Colorectal Surgery, Sao Carlos Hospital, Fortaleza, CE, Brazil

4 Department of Gynecology, School of Medicine, Federal University of Ceará, Fortaleza, CE, Brazil
TLUS and quantified according to the EDF classification. Fair concordance was found for intussusception. There was no correlation between the displacement of the puborectal muscle at maximum straining on EDF with the displacement of the anorectal junction (ARJ), compared at rest with maximal straining on TLUS to determine perineal descent (PD). The mean ARJ displacement was similar in patients with normal and those with excessive PD on TLUS.

Conclusions Both modalities can be used as a method to assess pelvic floor dysfunction. The EDF using 3D anorectal and endovaginal approaches showed advantages in identification of the anal sphincters and pubodefects (partial or total). There was good correlation between the two techniques, and a TLUS rectocele classification based on size that corresponds to the established classification using EDF was established.

Keywords Pelvic floor - Ultrasound · Constipation · Rectocele $\cdot$ Cystocele

\section{Introduction}

Pelvic floor dysfunction can have multiple components and include symptoms related to urinary and/or fecal incontinence (FI), pelvic organ prolapse and obstructed defecation with different clinical presentations. A complete clinical investigation to quantify the severity of the symptoms, detailed examination of the anal canal and perineal body and quantification of pelvic organ prolapse to determine the grade of the prolapse are required. A series of studies have shown similar results comparing dynamic diagnostic modalities including defecography, dynamic ultrasound through different approaches and/or dynamic magnetic 
resonance imaging to identify pelvic floor dysfunctions [1-8].

In 2004, Beer-Gabel et al. [4] reported using dynamic transperineal ultrasound to evaluate pelvic floor dysfunctions and compared it with defecography, demonstrating a high degree of concordance, and a series of studies followed their lead [9-12]. The other dynamic ultrasound options, such as dynamic three-dimensional (3D) anorectal ultrasound [Echodefecography (EDF)] [5] combined with the endovaginal approach [13, 14], have the advantage of making it easier to identify anatomical and dynamic pelvic floor abnormalities.

The aim of this study was to evaluate the role of dynamic translabial ultrasound (TLUS) for the assessment of pelvic floor dysfunction, comparing the results with EDF combined with the endovaginal approach (dynamic 3D anorectal and endovaginal ultrasound). The values to determine the grade of rectocele using TLUS were based on EDF.

\section{Materials and methods}

\section{Patients}

In the period from October 2015 to September 2016, consecutive female patients were invited to participate in the study if they had pelvic floor dysfunction including obstructed defecation symptoms (excessive straining, vaginal splinting or sensation of incomplete evacuation) despite having increased intake of dietary fiber (up to $30 \mathrm{~g} /$ day for 3 months), and a Cleveland Clinic Florida (CCF) constipation score $>6$ [15], with fecal and urinary incontinence (UI). The patients were assessed for FI, defined as the uncontrolled passage of feces or gas for at least 1 month in an individual of at least 4 years of age who had previously achieved control [16], and UI, defined as any involuntary leakage of urine with effort, exertion, sneezing, or coughing, and/or leaking or loss of urine associated with an urge to urinate [17].

Patients were excluded if they had organic pathology of the colon or rectum detected by clinical examination or colonoscopy.

The clinical protocol was approved by the Research Ethics Committee of the Walter Cantido University Hospital, and all patients gave written informed consent.

\section{Procedures}

Each patient underwent EDF combined with the endovaginal approach and TLUS to evaluate pelvic floor dysfunction. The examinations were performed by colorectal surgeons with experience in evaluating pelvic floor anatomy and dysfunction using dynamic imaging methods: EDF and endovaginal assessment were performed by A.S.V. and TLUS by S.M.M.R., with the examiners being blinded to the results of each technique and the patient's clinical. The results were compared.

\section{Echodefecography combined with the endovaginal approach}

The scan was performed with a 3D ultrasound device (ProFocus, endoprobe model 2052, B-K Medical, Herlev, Denmark) placed in the rectum, with proximal-to-distal $6.0 \mathrm{~cm}$ automatic scans. Patients received a rectal enema and were examined in the left lateral position. Images were acquired by four automatic scans [5, 18].

Scan I (at rest) verified the anatomical integrity of the anal sphincters. Defects were considered to be partial (partially compromised length of the muscle) or total (whole length of the muscle compromised) (Fig. 1).

Scan 2 evaluated the movement of the puborectalis muscle and the external anal sphincter during straining, identifying normal relaxation, non-relaxation or paradoxical contraction (anismus).

Scan 3 quantified the perineal descent (puborectalis muscle (PR) descent) by measuring the distance between the position of the proximal border of the PR muscle at rest and the point to which it was displaced by maximum

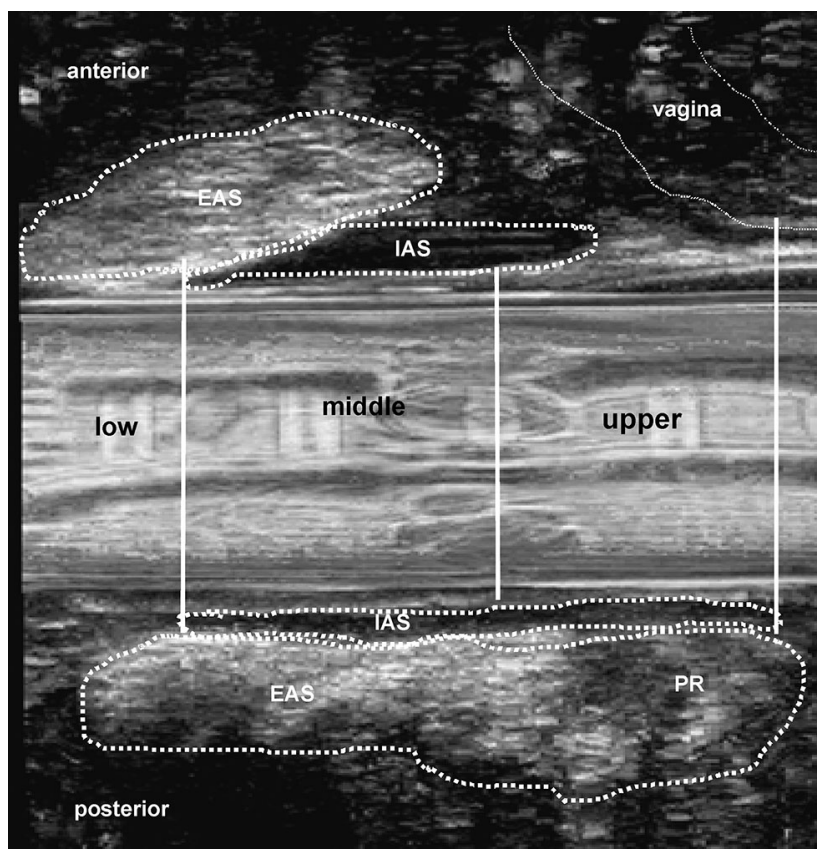

Fig. 1 Three-dimensional anorectal ultrasound image of anal sphincter intact. $E A S$ external anal sphincter, $I A S$ internal anal sphincter, $P R$ puborectalis muscle 
straining. Perineal descent $\leq 2.5 \mathrm{~cm}$ was classified as normal, while PD $>2.5 \mathrm{~cm}$ was classified as excessive.

For scan 4, 60-120 ml ultrasound gel was injected into the rectal ampulla. This scan identified and quantified the depth of rectocele as well as intussusception, sigmoidocele/ enterocele (grade II or III) and cystocele (measured by a displacement of the bladder or bladder neck below the proximal margin of the $P R \geq 0.5 \mathrm{~cm}$ ). Rectocele depth was measured by drawing two parallel horizontal lines adjacent to the posterior vaginal wall, one in the initial straining position and one at the point of maximal straining. The distance between the two vaginal wall positions was used to determine the rectocele depth. Rectocele depth was classified as grade I $(<0.6 \mathrm{~cm} \mathrm{~mm})$, grade II $(0.6-1.3 \mathrm{~cm})$ or grade III $(>1.3 \mathrm{~cm})$.

All patients who had a vaginal delivery underwent 3D endovaginal ultrasound to evaluate the anatomical integrity of the pubovisceral muscles (PVM) (including the puborectalis and pubococcygeus muscles) (Fig. 2) or defects $[13,14]$. Patients were placed in the dorsal lithotomy position. The same transducer, using $12 \mathrm{MHz}$ and a focal distance of $5.2 \mathrm{~cm}$, was placed in the vagina in the neutral position, and the endoprobe was introduced as far as the bladder. Pubovisceral defects were defined as complete or partial detachment (discontinuity) of the muscle from the pubic rami.

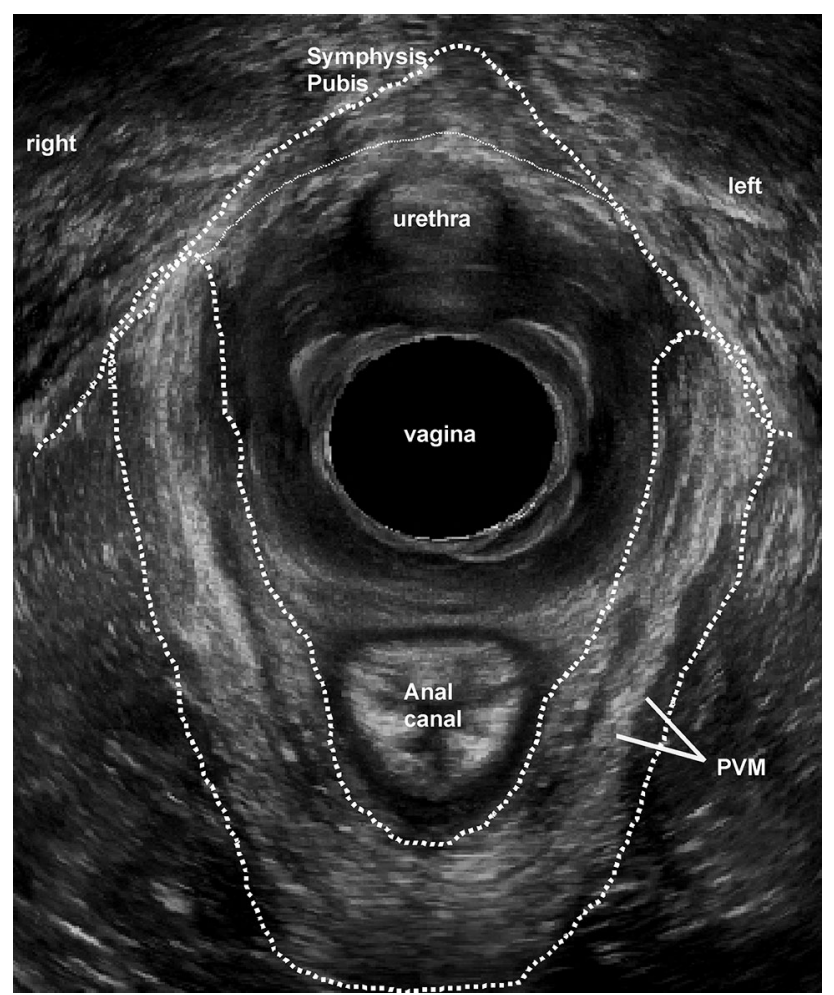

Fig. 2 Three-dimensional endovaginal ultrasound image of pubovisceral muscles intact (PMV)

\section{Translabial ultrasound}

TLUS was performed with conventional convex transducers, with frequencies of $6 \mathrm{MHz}$ and field of view at least $70^{\circ}$ (B-K Medical Type 8802, ProFocus Peabody, Massachussets USA), placed on the perineum, which provided two-dimensional imaging of the pelvic floor. Patients received a rectal enema and were examined in the dorsal lithotomy position, with hips flexed and abducted. Imaging is usually performed with the patient at rest and during maximal Valsalva maneuver [4, 9].

In the mid-sagittal plane, all anatomical structures can be seen from posterior to anterior (bladder, urethra, vagina, anal canal and rectum) between the posterior surface of the pubic symphysis and the posterior part of the levator ani (Fig. 3).

Anismus was characterized by a failure to execute the relaxation of the puborectalis muscle and the external anal sphincter that is required for successful defecation. It was measured by the anorectal angle (the confluence of lines through the hypoechoic band representing the posterior internal anal sphincter and through the posterior wall of the rectal ampulla) at rest and during evacuation. Thus, anismus was recorded when the anorectal angle failed to open or became narrower during straining compared to the anorectal angle at rest. In cases with normal relaxation, the angle increases.

The rectum was filled with $60 \mathrm{~mL}$ of acoustic gel to identify rectocele and quantify rectocele depth. The rectocele depth was measured perpendicular to a line

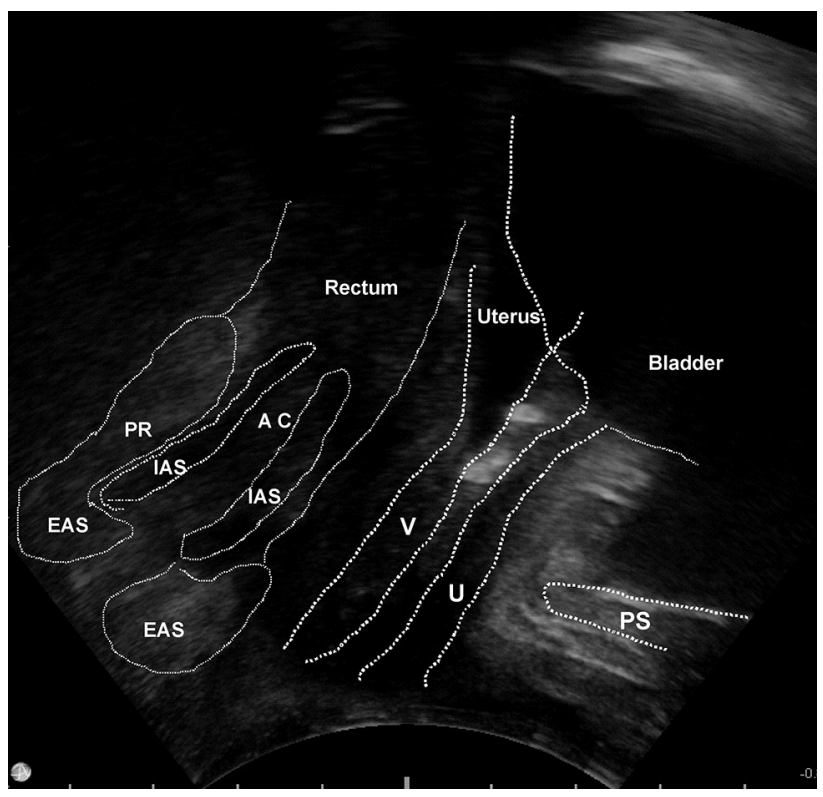

Fig. 3 Translabial ultrasound image of pelvic floor. $P S$ pubic symphysis, $U$ urethra, $V$ vagina, EAS external anal sphincter, IAS internal anal sphincter, $P R$ puborectalis muscle 
projected along the contour of the anterior rectal wall. The depth of rectocele using the TLUS technique was established measuring the rectocele sizes in the same patients and comparing with EDF results.

Rectal intussusception was characterized as an invagination of the rectal wall into the rectal lumen during maximal Valsalva maneuver. Entero-sigmoiodocele was diagnosed when there was the presence of bowel loops into the pelvis between the rectum and vagina. Cystocele was identified using a reference line drawn parallel to the inferoposterior margin of the pubic symphysis and the downward displacement of the bladder beyond the inferoposterior margin of the pubic symphysis during the Valsalva maneuver.

Perineal descent was measured by the displacement of the anorectal junction (ARJ) in relation to pubic symphysis, calculating the difference of the vertical line between the ARJ and a reference line drawn parallel to the inferoposterior margin of pubic symphysis, comparing the distance between at rest and maximal straining position.

\section{Statistical analysis}

Differences between anorectal angle and anorectal position were assessed using Student's $t$ test. The Spearman rank correlation coefficient $(\rho)$ was calculated to evaluate the relationship between the displacement of the PR muscles upon maximum straining on EDF, with the difference of the distance between the anorectal junction and a line from the pubic symphysis at rest compared to maximal straining on TLUS. The diagnostic accuracy of TLUS was evaluated considering the results of echodefecography as the standard for comparison. As an index of concordance between the methods, kappa $(\kappa)$ coefficients were calculated with $95 \%$ CI [19]. Concordance based on the $\kappa$ value was classified as slight $(0-0.20)$, fair (0.21-0.40), moderate (0.41-0.60), substantial (0.61-0.80), near perfect (0.81-0.99) or perfect (1.0) [19]. Results were considered statistically significant when $p<0.05$.

\section{Results}

A total of 42 women were included in the study, with a mean age of 56 years (range 26-85). All of them complained of ODS. The median CCF constipation score 9 (range 7-21), 16 (38\%) complained of FI and 17 (40\%) of UI. Overall, $29(69 \%)$ had vaginal deliveries, 6 had undergone cesarean sections and 7 were nulliparous.

\section{Echodefecography}

A total of seven (17\%) had sphincter and/or PVM defects: Two had partial external anal sphincter (EAS), two combined partial EAS plus internal anal sphincter (IAS) associated with unilateral PVM muscles defects and three had PVM defects with intact sphincters. Five of these patients complained of FI symptoms.

The anorectal angle increased from a mean of $87^{\circ} \pm 5.5^{\circ}-98^{\circ} \pm 12.2^{\circ}$ (mean difference, $+11^{\circ} \%$ $p=0.00)$ in $22(52 \%)$ patients, and failed to open in 20 (48\%) patients, decreasing from a mean of $86^{\circ} \pm 4.6^{\circ}$ to $80^{\circ} \pm 5.7^{\circ}$, with a mean difference of $-6^{\circ}(p=0.00)$.

Rectocele was identified in $27(64 \%)$ patients and classified as grade I in 4 patients, grade II in 5 and grade III in 18 , and as a significant rectocele (grade II or III) in a total of $23(55 \%)$ patients. Rectal intussusception was found in $17(40 \%)$ patients. Eleven of the patients with intussusception also had significant rectocele. An enterocele-sigmoidocele was observed in one patient. Perineal descent was identified in 10 (24\%) patients, and the mean displacement of PR muscles was $2.9 \mathrm{~cm}$ (range $2.6-3.5 \mathrm{~cm})$. Cystocele was identified in $20(48 \%)$ patients, 10 of whom complained of urinary incontinence.

\section{Translabial ultrasound (TLUS)}

TLUS identified sphincter defects in four (10\%) patients without demonstrating if the defect was a partial (partially compromised length of the muscle) or total (whole length of the muscle compromised). Two of these patients had EAS defects and two EAS plus IAS. Three complained of FI symptoms. No PVM defects were identified.

The anorectal angle increased from a mean of $106^{\circ} \pm 29.6^{\circ}-148^{\circ} \pm 30.7^{\circ}$ (mean difference, $+12^{\circ}$ ) in 19 (45\%) patients, and failed to open in $23(55 \%)$ patients, decreasing from a mean of $110^{\circ} \pm 25^{\circ}$ to $98^{\circ} \pm 21^{\circ}$, with a mean difference of $-6^{\circ}(p=0.043)$.

Rectocele was identified in 25 patients. Different depths of rectocele were measured at TLUS and quantified according to the EDF classification: The depth was $>2.0 \mathrm{~cm}$ for grade III, from 1.1 to $2.0 \mathrm{~cm}$ for grade II and $\leq 1.0 \mathrm{~cm}$ for grade I. A total of 17 patients were classified with grade III; 6 with grade II and 2 with grade I.

Rectal intussusception was found in three (7\%) patients, all of whom had rectocele.

An enterocele-sigmoidocele was observed in one patient.

The mean ARJ position at rest was $2.2 \pm 0.8 \mathrm{~cm}$ (range $0.0-4.9 \mathrm{~cm}$ ) and $1.1 \pm 1.0 \mathrm{~cm}$ (range -1.0 to $2.8 / p=0.00$ ) during maximal straining. The mean displacement of the anorectal junction was $1.1 \pm 0.87 \mathrm{~cm}$ (range 0.0-2.9).

Cystocele was identified in 19 (45\%) patients.

\section{Concordance between EDF and TLUS}

The both modalities identified the sphincter muscles defects, but TLUS did not determine the length of the sphincter and PVM defects. 
Table 1 Concordance between echodefecography (EDF) and translabial ultrasound (TLUS) regarding normal relaxation and anismus diagnosis

\begin{tabular}{lccc}
\hline & \multicolumn{2}{l}{ Translabial ultrasound } & Total diagnosed by EDF \\
\cline { 2 - 3 } & Normal relaxation & Anismus & \\
\hline Echodefecography & $17^{*}$ & 5 & 22 \\
Normal relaxation & 2 & $18^{*}$ & 20 \\
Anismus & 19 & 23 & 44 \\
Total diagnosed by TLUS & & & 23 \\
\hline
\end{tabular}

* Concordant findings
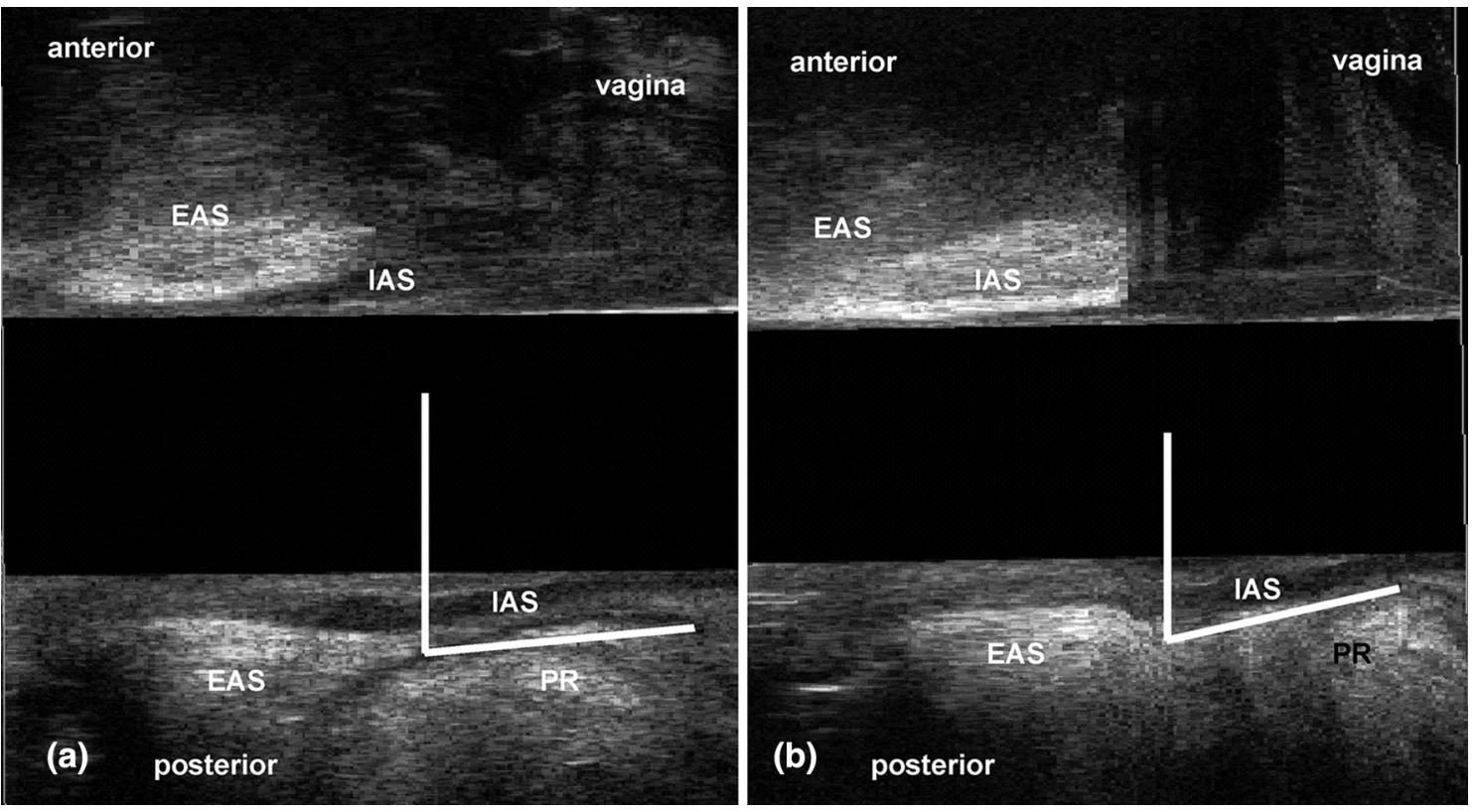

Fig. 4 Comparison of the anorectal angle at rest and during straining in patients with anismus assessed with echodefecography. EAS external anal sphincter, IAS internal anal sphincter, $P R$ puborectalis

Anismus was identified in 18 (43\%) patients and normal relaxation in $17(40 \%)$ with both techniques. Substantial concordance was observed between EDF and TLUS $(\kappa=0.68,95 \%$ CI $0.37-0.97)$ (Table 1; Figs. 4, 5).

Rectocele was identified in $27(64 \%)$ and $25(59 \%)$ patients by EDF and TLUS, respectively, with perfect concordance ( $\kappa=0.98,95 \%$ CI $0.69-1.0)$. The two techniques demonstrated identical findings in 15 patients without rectocele, and in 2, 5, and 17 with grade I, II, and III, respectively (Fig. 6). Different rectocele depths were measured with TLUS and quantified according to the EDF classification, i.e., $>2.0 \mathrm{~cm}$ for grade III, from 1.1 to $2.0 \mathrm{~cm}$ for grade II and $\leq 1.0 \mathrm{~cm}$ for grade I. Two cases of grade I identified by EDF were not identified on TLUS (Table 2).

Intussusception was identified in 17 (40\%) patients on EDF and confirmed in $3(7 \%)$ by TLUS with fair concordance $(\kappa=0.20,95 \%$ CI $0.02-0.39)$ (Table 3; Fig. 7). Entero-sigmoicele was identified in one ( $2 \%$ ) patient by both techniques. muscles. a Angle measured at rest (white lines). b Decreased angle during straining (white lines)

Cystocele was identified in 20 patients by EDF and confirmed in 18 by TLUS with perfect concordance $(\kappa=0.85,95 \%$ CI $0.55-1.0)$ (Table 4; Fig. 8).

On EDF, excessive PD, and PR muscle displacement $>2.5 \mathrm{~cm}$ was detected in 10 patients and the mean ARJ displacement was $1.2 \pm 0.86 \mathrm{~cm}$ (range $0.1-2.9 \mathrm{~cm}$ ), using TLUS 32 patients had normal PD, and PR muscle displacement $\leq 2.5 \mathrm{~cm}$, on EDF and the mean ARJ displacement was $1.1 \pm 0.86 \mathrm{~cm}$ (range 0.0-2.9), using TLUS. The displacement of the ARJ on TLUS was similar when comparing patients with normal PD and excessive PD. (Table 5; Fig. 9).

There was no positive correlation between the displacement of PR muscles at maximum straining on EDF (mean $=2.2 \pm 0.58 \mathrm{~cm}$, range $0.8-3.5$ ) with the displacement of the ARJ (mean $=1.1 \pm 0.85 \mathrm{~cm}$, range $0.0-2.9)$, at rest versus at maximal straining on TLUS $(r=-0.03 ; p=0.86)$. 


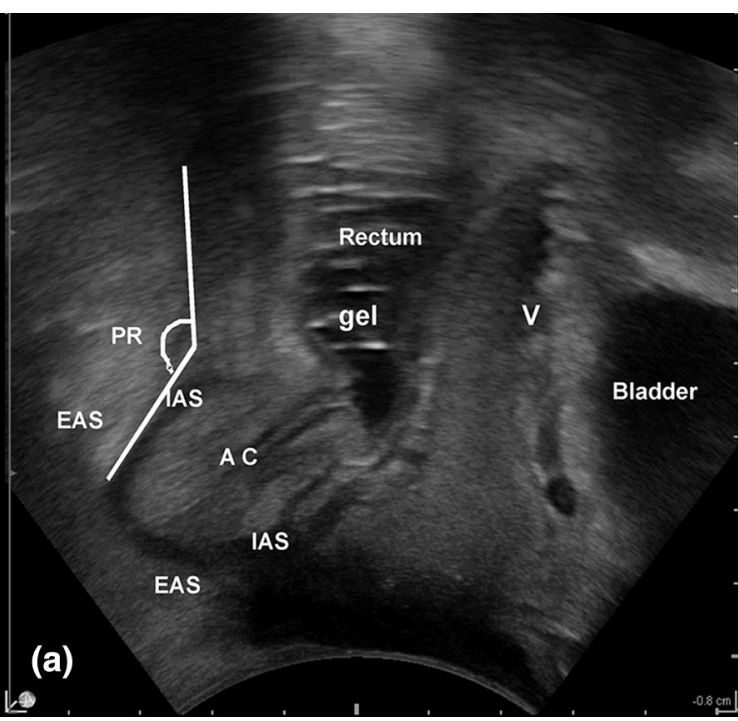

Fig. 5 Comparison of anorectal angle at rest and during straining in patients with anismus as assessed with translabial ultrasound. EAS external anal sphincter, IAS internal anal sphincter, $P R$ puborectal

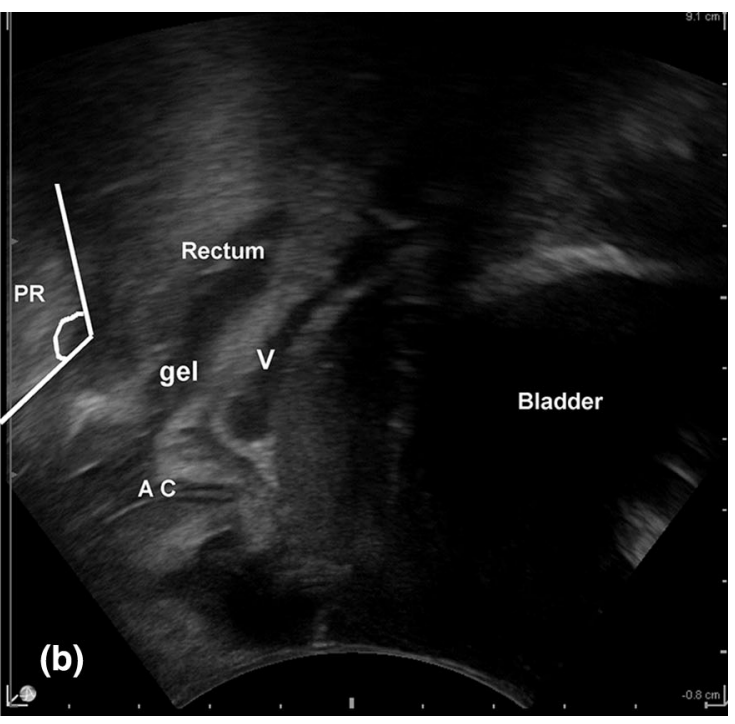

muscles, $A C$ anal canal, $V$ vagina. a Angle measured at rest (white lines). b Decreased angle during straining (white lines)

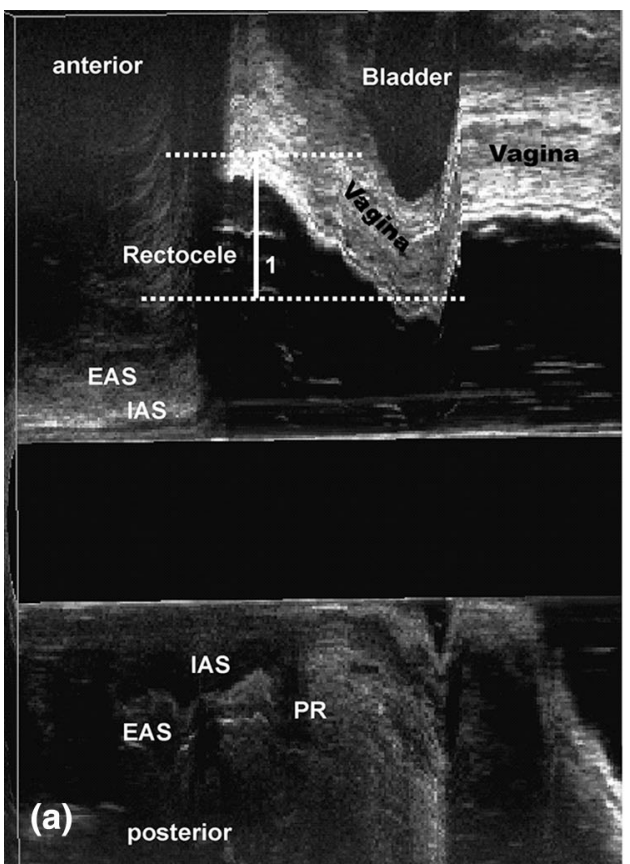

Fig. 6 Detection of rectocele (grade classified). a Echodefecography-Line $1=$ measures the depth of the rectocele. $\mathbf{b}$ Translabial ultrasound-Line $2=$ measures the depth of the rectocele (b). PS

\section{Discussion}

The present study showed that TLUS has a good correlation with EDF for the diagnoses of anismus, rectocele and cystocele. We chose EDF combined with the endovaginal approach as the standard for comparison with TLUS because it has been standardized [5] in comparison with

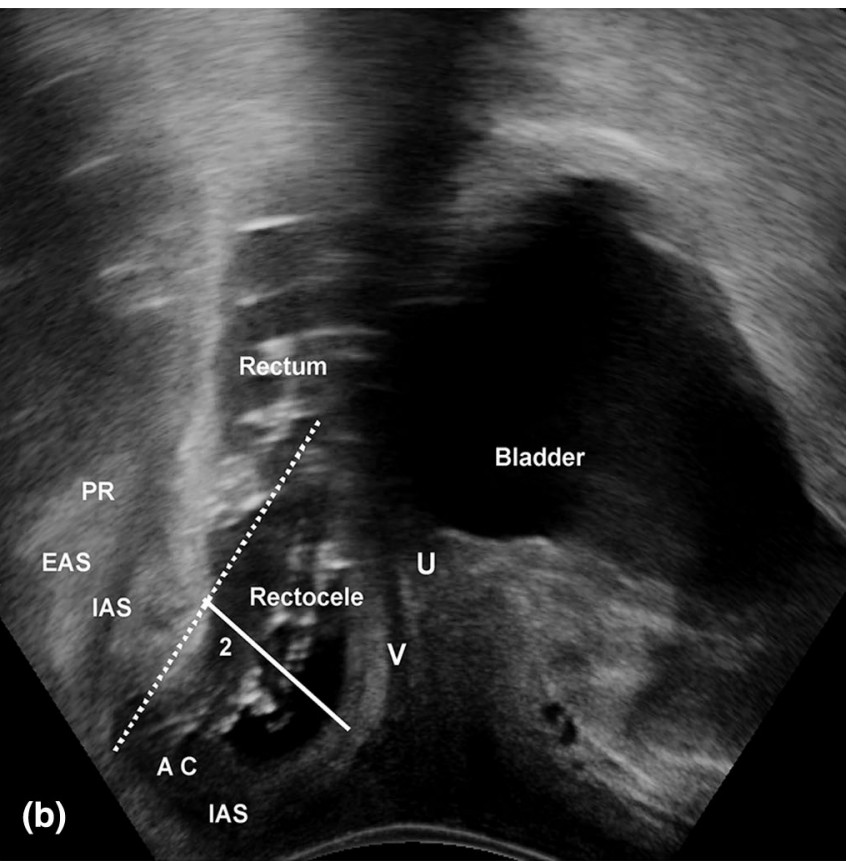

pubic symphysis, $U$ urethra, $V$ vagina, $A C$ anal canal, $E A S$ external anal sphincter, $I A S$ internal anal sphincter, $P R$ puborectalis muscle

defecography, and validated in a multicenter study [20]. Previous studies have demonstrated the anatomy of the PVM and identified defects in patients who had a vaginal delivery, using 3D endovaginal ultrasound, as well as positive correlation between sphincter and/or PVM defect and the severity of the CCF incontinence score in females with FI [14]. Therefore, the techniques (EDF with 
Table 2 Concordance between echodefecography (EDF) and translabial ultrasound (TLUS) regarding rectocele and grade

\begin{tabular}{|c|c|c|c|c|c|}
\hline & \multicolumn{4}{|c|}{ Translabial ultrasound } & \multirow[t]{2}{*}{ Diagnosed by EDF } \\
\hline & Without rectocele & Rectocele I & Rectocele II & Rectocele III & \\
\hline \multicolumn{6}{|l|}{ Echodefecography } \\
\hline Without rectocele & $15 *$ & 0 & 0 & 0 & 15 \\
\hline Rectocele I & 2 & $2 *$ & 0 & 0 & 04 \\
\hline Rectocele II & 0 & 0 & $5 *$ & 0 & 05 \\
\hline Rectocele III & 0 & 0 & 1 & $17^{*}$ & 18 \\
\hline Diagnosed by TLUS & 17 & 02 & 06 & 17 & 42 \\
\hline
\end{tabular}

* Concordant findings

Table 3 Concordance between echodefecography (EDF) and translabial ultrasound (TLUS) regarding diagnosis of intussusception

\begin{tabular}{lccc}
\hline & \multicolumn{2}{l}{ Translabial ultrasound } & Diagnosed by EDF \\
\cline { 2 - 3 } & Without & Intussusception & \\
\hline Echodefecography & $25^{*}$ & 0 & 25 \\
Without & 14 & $3^{*}$ & 17 \\
Intussusception & 39 & 03 & 42 \\
Diagnosed by TLUS & & & \\
\hline
\end{tabular}

* Concordant findings
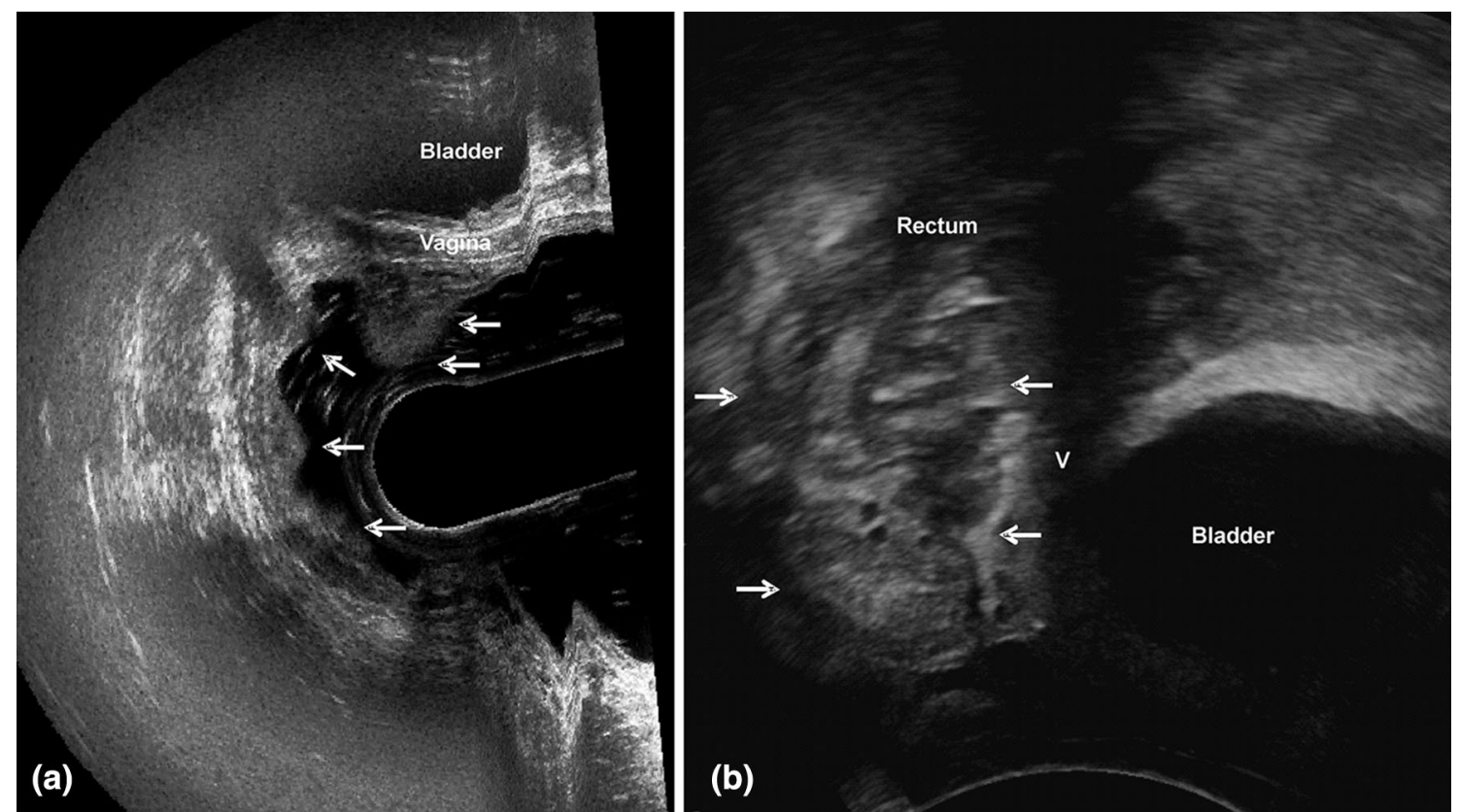

Fig. 7 Detection of intussusception (arrows) with echodefecography (a) versus translabial ultrasound (b)

endovaginal) were combined using the same transducer, making a complete evaluation possible. A total of $29(60 \%)$ of the patients of this study had a vaginal delivery and 7 (24\%) had isolated or combined sphincter defects and/or PVM defects. All patients who had a vaginal delivery should be evaluated with both modalities, even without FI symptoms, to identify occult lesions [21-24].
Overall, multiple pelvic floor disorders were prevalent in this group of patients, because the study population included females with multiple symptoms, such as ODS associated with UI and/or FI in approximately 40\%, similar to a series of published studies [25-27].

All the patients in the present study received a rectal enema $2 \mathrm{~h}$ before the examination in order to avoid 
Table 4 Concordance between both techniques regarding cystocele

\begin{tabular}{lrrr}
\hline & \multicolumn{2}{c}{ Translabial Ultrasound } & Diagnosed by EDF \\
\cline { 2 - 3 } & Without & Cystocele & \\
\hline Echodefecography & & & \\
Without & $21^{*}$ & 1 & 22 \\
Cystocele & 2 & $18^{*}$ & 20 \\
Diagnosed by TLUS & 23 & 19 & 42 \\
\hline
\end{tabular}

* Concordant findings

artefacts, such as feces and air. As in the original study described by Beer-Gabel et al. [3], the rectum was filled with ultrasonographic coupling gel $(60 \mathrm{ml})$ to visualize the anatomical structures and cause the patients to feel the stimulus to evacuate.

The values of the angles at rest and during straining were not compared between the techniques because the landmarks used to draw the angles were not similar. However, the results in patients identified as having normal relaxation or anismus showed substantial concordance. Grasso et al. [19] in contrast, Perniola et al. [12] also compared TLUS with defecation proctography and found poor concordance in the measurements of the anorectal angle.
The present study revealed high concordance rates between EDF and TLUS for detecting rectocele, with only two cases of grade I rectocele not detected on TLUS. Previous studies using TLUS have quantified rectocele from the herniation of at least $10 \mathrm{~mm}$ in depth of the rectal contents into the vagina [4]. Perniola et al. [12] comparing TLUS and proctography considered defecation proctography to be the gold standard and used the same values to measure rectocele depth, which showed very poor concordance. Therefore, in the present study the cutoff values for each grade of rectocele using TLUS were determined based on EDF instead of using the same measurements previously determined by defecography, considering that the techniques, markers and positions of the patients were different.

A total of 17 cases of intussusception were found using $\mathrm{EDF}$, with the majority of these associated with significant rectocele, however, only three cases were detected on TLUS, revealing fair concordance. Even with gel inserted into the rectum to distend it and make it possible to visualize the layers of the rectal wall, TLUS was unable to identify the majority of intussusception cases. These results are in accordance with those reported in the literature $[9,12]$.
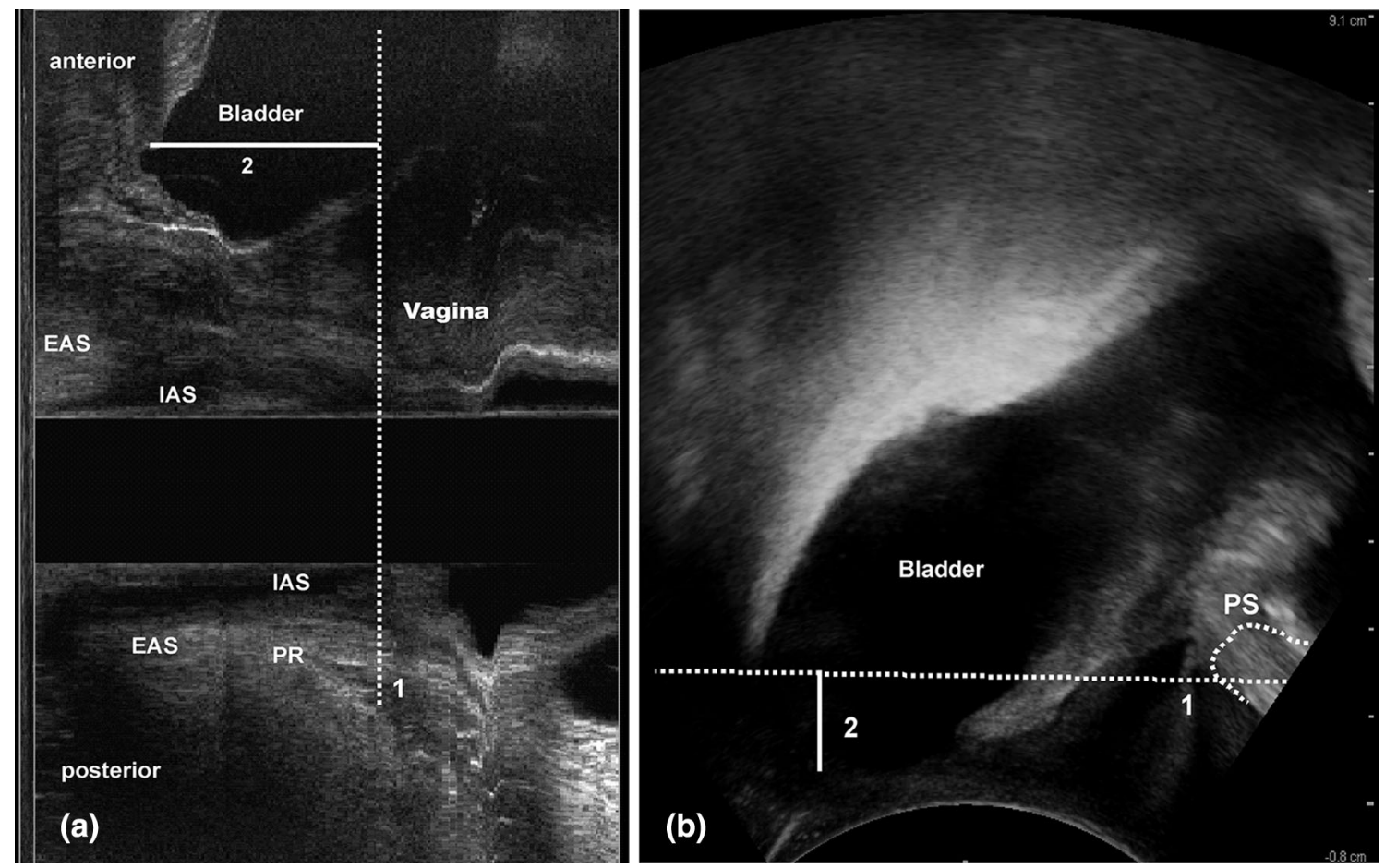

Fig. 8 Detection of cystocele. a Echodefecography-Line $1=$ line dawn in the proximal margin of the puborectalis muscles (PR)/Line $2=$ measures the displacement of the bladder or bladder neck below the proximal margin of the PR. b Translabial ultrasound-Line $1=$ line drawn parallel to the inferoposterior margin of the pubic
symphysis/Line $2=$ measures the displacement of the bladder beyond the inferoposterior margin of the pubic symphysis during the Valsalva maneuver. $P S$ pubic symphysis, EAS external anal sphincter, IAS internal anal sphincter, $P R$ puborectalis muscles 
Table 5 Perineal descent measurements: echodefecography (EDF) compared with translabial ultrasound (TLUS)

\begin{tabular}{lll}
\hline Perineal descent measurements & $\begin{array}{l}\text { Normal perineal descent } \\
N=32 \text { patients }(\mathrm{cm})\end{array}$ & $\begin{array}{l}\text { Excessive perineal descent } \\
N=10 \text { patients }(\mathrm{cm})\end{array}$ \\
\hline Puborectalis muscle displacement on EDF mean (SD) & $1.9(0.39)$ & $3.0(0.28)$ \\
Anorectal junction displacement on TLUS mean (SD) & $1.1( \pm 0.86)$ & $1.2( \pm 0.86)$ \\
\hline
\end{tabular}

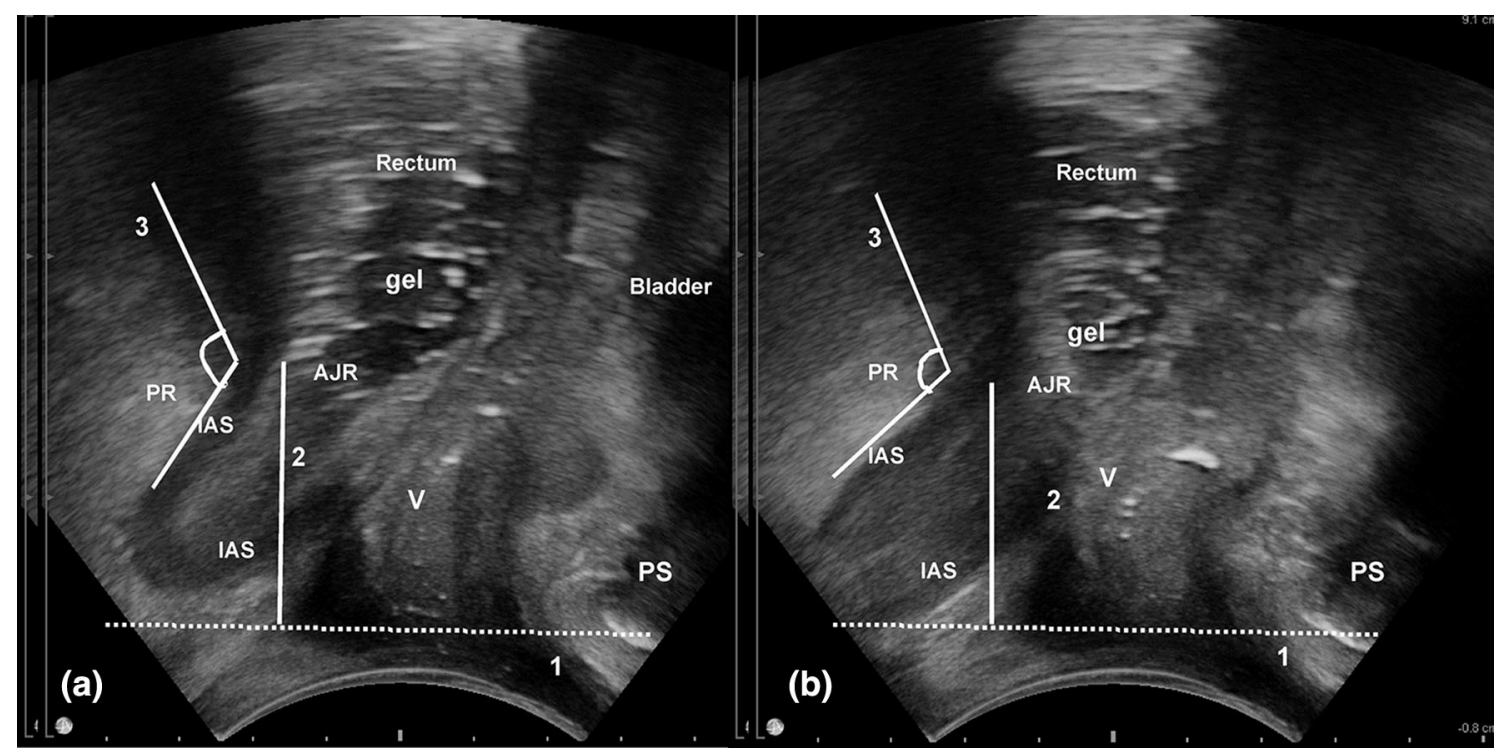

Fig. 9 Perineal descent measurements at rest (a) and during the Valsalva maneuver (b). Line $1=$ Line drawn parallel to the inferoposterior margin of pubic symphysis/Line $2=$ Vertical line from the anorectal junction to the line drawn parallel to the inferoposterior margin of pubic symphysis comparing the at rest

Only 1 case of enterocele was detected in this study, diagnosed by both techniques. Few studies have compared transperineal ultrasound with dynamic evacuation proctography and the majority of studies do not mention the diagnosis of enterocele $[10,12]$.

The technique of assessment of cystocele was described using a reference line drawn parallel to the inferoposterior margin of the pubic symphysis and the downward displacement of the bladder beyond the inferoposterior margin of the pubic symphysis during the Valsalva maneuver. Cystocele was also considered if the bladder was descending and in ascertaining the configuration of the bladder neck and urethra [28, 29]. Lone et al. [30] evaluated the displacement of pelvic organs using this reference line and compared this with the validated Pelvic Organ Prolapse Quantification System (POP-Q), showing that the proportion of correct predictions was $60 \%$ for bladder displacement. The present study evaluated bladder displacement using TLUS comparing this with EDF that measured the displacement of the bladder or bladder neck $\geq 0.5 \mathrm{~cm}$ below the proximal margin of the PR. Thus, even when a different technique and anatomical reference points (a) with during the Valsalva maneuver (b). Line $3=$ The anorectal angle at rest (a) and during the Valsalva maneuver (b). EAS external anal sphincter, IAS internal anal sphincter, $P R$ puborectalis muscles, $P S$ pubic symphysis

were used the results demonstrated good concordance. In those patients with symptoms of UI, cystocele should be evaluated with complementary methods in order to choose the best modalities of treatment.

Beer-Gabel et al. [4] described the original technique for determining perineal descent comparing with defecography. The results were similar concerning the position of the ARJ at rest and during straining. The present study demonstrated that there was a significant displacement in the ARJ position when comparing at rest with maximal straining. On the other hand, the displacement of the ARJ by TLUS was similar when comparing patients with normal PD and with excessive PD and there was no positive correlation between the displacement of PR muscles at maximum straining by EDF with the displacement of the ARJ by TLUS. In the 10 patients identified on EDF as having excessive PD, the difference between the ARJ position in relation to then line from pubic symphysis when comparing at rest to maximal straining was not enough to quantity as an excessive PD by TLUS.

A series of studies have demonstrated that the advantages and disadvantages of the modalities to evaluate the 
pelvic floor dysfunction. Vitton et al. [8] compared dynamic ultrasound with dynamic magnetic resonance imaging using defecography as a gold standard. They obtained similar results regarding pelvic floor dysfunction and found that patient tolerance was significantly better for dynamic anorectal endosonography (72\%) than for dynamic resonance $(25 \%)$ or defecography $(2 \%)$. The other advantage to using ultrasound is cost-effectiveness, as it can be performed in the doctor's consulting room.

Further studies should compare TLUS with dynamic magnetic resonance imaging to demonstrate the correlation between the techniques. A multicenter study should also be performed to evaluate the results of different examiners and the inter-observer reliability.

\section{Conclusions}

Dynamic ultrasound is a good option for evaluating patients with pelvic floor dysfunction and can be considered first line depending on the symptoms of the patients and the availability of the ultrasound examination. There is a good correlation when EDF and TLUS and both techniques can be used to evaluate pelvic dysfunction. However, EDF is more effective in evaluating the muscle integrity and identifying defects.

\section{Compliance with ethical standards}

Conflict of interest The authors declare that they have no conflict of interest.

Ethical approval The clinical protocol was approved by the Research Ethics Committee of the Walter Cantido University Hospital.

Informed consent All patients gave written informed consent.

\section{References}

1. Broekhuis SR, Kluivers KB, Fütterer JJ, Barentsz JO, Vierhout ME (2009) POP-Q, dynamic MR imaging, and perineal ultrasonography: do they agree in the quantification of female pelvic organ prolapse? Int Urogynecol J Pelvic Floor Dysfunct 20:541-549

2. Derpapas A, Digesu GA, Fernando R, Khullar V (2011) Imaging in urogynaecology. Int Urogynecol J 22:1345-1356

3. Barthet M, Portier F, Heyries L (2000) Dynamic anal endosonography may challenge defecography for assessing dynamic anorectal disorders: results of a prospective pilot study. Endoscopy 32:300-305

4. Beer-Gabel M, Teshler M, Schechtman E, Zbar AP (2004) Dynamic transperineal ultrasound versus defecography in patients with evacuatory difficulty: a pilot study. Int J Colorectal Dis 19:60-67

5. Murad-Regadas SM, Regadas FSP, Rodrigues LV, Silva FRS, Soares FA, Escalante RD (2008) A novel three-dimensional dynamic anorectal ultrasonography technique (echodefecography) to assess obstructed defecation, a comparison with defecography. Surg Endosc 22:974-979

6. Kaufman HS, Buller JL, Thompson JR et al (2001) Dynamic pelvic magnetic resonance imaging and cystocolpoproctography alter surgical management of pelvic floor disorders. Dis Colon Rectum 44:1575-1583

7. Dvorkin LS, Hetzer F, Scott SM, Williams NS, Gedroyc W, Lunniss PJ (2004) Open-magnet MR defaecography compared with evacuation proctography in the diagnosis and management of patients with rectal intussusception. Colorectal Dis 6:45-53

8. Vitton V, Vignally P, Barthet M et al (2001) Dynamic anal endosonography and MRI defecography in diagnosis of pelvic floor disorders: comparison with conventional defecography. Dis Colon Rectum 54:1398-1404

9. Dietz HP, Steensma AB (2005) Posterior compartment prolapse on two-dimensional and three dimensional pelvic floor ultrasound: the distinction between true rectocele, perineal hypermobility and enterocele. Ultrasound Obstet Gynecol 26:73-77

10. Grasso RF, Piciucchi S, Quattrocchi CC, Sammarra M, Ripetti V, Zobel BB (2007) Posterior pelvic floor disorders: a prospective comparison using introital ultrasound and colpocystodefecography. Ultrasound Obstet Gynecol 30:86-94

11. Beer-Gabel M, Assoulin Y, Amitai M, Bardan E (2008) A comparison of dynamic transperineal ultrasound (DTP-US) with dynamic evacuation proctography (DEP) in the diagnosis of cul de sac hernia (enterocele) in patients with evacuatory dysfunction. Int J Colorectal Dis 23:513-519

12. Perniola G, Shek C, Chong CC, Chew S, Cartmill J, Dietz HP (2008) Defecation proctography and translabial ultrasound in the investigation of defecatory disorders. Ultrasound Obstet Gynecol 31:567-571

13. Murad-Regadas SM, Bezerra LR, Silveira CR et al (2013) Anatomical and functional characteristics of the pelvic floor in nulliparous women submitted to three-dimensional endovaginal ultrasonography: case control study and evaluation of interobserver agreement. Rev Bras Ginecol Obstet 35:123-129

14. Murad-Regadas SM, Fernandes GO, Regadas FS et al (2014) Assessment of pubovisceral muscle defects and levator hiatal dimensions in women with faecal incontinence after vaginal delivery: is there a correlation with severity of symptoms? Colorectal Dis 16:1010-1018

15. Agachan F, Chen T, Pfeiffer J, Reissman P, Wexner SD (1996) A constipation scoring system to simplify evaluation and management of constipated patients. Dis Colon Rectum 39:681-685

16. Tjandra JJ, Dykes SL, Kumar RR et al (2007) Practice parameters for the treatment of fecal incontinence. Dis Colon Rectum 50:1497-1507

17. Abrams P, Blaivas JG, Stanton SL, Andersen JT (1990) The standardization of terminology of lower urinary tract function recommended by the international continence society. Int Urogynecol J 1:45-58

18. Murad-Regadas SM, dos Santos D, Soares G et al (2012) A novel three-dimensional dynamic anorectal ultrasonography technique for the assessment of perineal descent, compared with defaecography. Colorectal Dis 14:740-747

19. Lee J, Fung KP (1993) Confidence interval of the kappa coefficient by bootstrap resampling. Psychiatry Res 49:97-98

20. Regadas FS, Haas EM, Abbas MA et al (2011) Prospective multicenter trial comparing echodefecography with defecography in the assessment of anorectal dysfunction in patients with obstructed defecation. Dis Colon Rectum 54:686-692

21. Deen KI, Kumar D, Williams JG et al (1993) The prevalence of anal sphincter defects in faecal incontinence: a prospective endosonic study. Gut 34:685-688 
22. Sultan AH, Kamm MA, Talbot IC et al (1994) Anal endosonography for identifying external sphincter defects confirmed histologically. Br J Surg 81:463-465

23. Williams AB, Bartram CI, Halligan S et al (2001) Anal sphincter damage after vaginal delivery using three-dimensional endosonography. Obstet Gynecol 97:770-775

24. Dietz HP, Lanzarone V (2005) Levator trauma after vaginal delivery. Obstet Gynecol 106:707-712

25. MacLennan AH, Taylor AW, Wilson DH, Wilson D (2000) The prevalence of pelvic floor disorders and their relationship to gender, age, parity and mode of delivery. Br J Obstet Gynaecol 107:1460-1470

26. Lukacz ES, Lawrence JM, Contreras R, Nager CW, Luber KM (2006) Parity, mode of delivery, and pelvic floor disorders. Obstet Gynecol 107:1253-1260
27. Kepenekci I, Keskinkilic B, Akinsu F, Cakir P, Elhan AH, Erkek AB, Kuzu MA (2011) Prevalence of pelvic floor disorders in the female population and the impact of age, mode of delivery, and parity. Dis Colon Rectum 54:85-94

28. Dietz HP (2010) Pelvic floor ultrasound: a review. Am J Obstet Gynecol 202:321-334

29. Tunn R, Petri E (2003) Introital and transvaginal ultrasound as the main tool in the assessment of urogenital and pelvic floor dysfunction: an imaging panel and practical approach. Ultrasound Obstet Gynecol 22:205-213

30. Lone FW, Thakar R, Sultan AH, Stankiewicz A (2012) Accuracy of assessing pelvic organ prolapse quantification points using dynamic 2D transperineal ultrasound in women with pelvic organ prolapse. Int Urogynecol J 23:1555-1560 